\title{
Pregnancy Outcomes of Non-Visualization of The Foetal Gallbladder From A Chinese Tertiary Single Centre And Literature Review
}

Huijing Zhang

Peking University First Hospital

Xiaoying Zhu

Hengshui Renmin Hospital

Jinling Kang

Dezhou Women and Children's Hospital

Huixia Yang

Peking University First Hospital

Yu Sun ( $\square$ sunyu1705@126.com )

Peking University First Hospital

\section{Research Article}

Keywords: non-visualization of fetal gallbladder (NVFGB), pregnancy outcome, prenatal diagnosis, prognosis

Posted Date: January 7th, 2022

DOI: https://doi.org/10.21203/rs.3.rs-1185379/v1

License: (c) (i) This work is licensed under a Creative Commons Attribution 4.0 International License. Read Full License 


\section{Abstract}

Objection To explore the clinical features and prognosis of non-visualization of fetal gallbladder (NVFGB). Methods 65 cases diagnosed of NVFGB in the Peking University First Hospital was collected retrospectively from January, 2019 to December, 2020. Results 49 cases were successfully followed up. Among them, the gallbladder of 21 fetuses (42.9\%) was visible later, either in the later pregnancy or after birth. In the rest 28 cases (57.1\%), the gallbladders were not seen during the whole pregnancy. 11 of 28 fetuses (39.3\%) with NVFGB were complicated with other structure anomaly. In the remaining 17 cases of isolated NVFGB (60.7\%), one case was diagnosed of congenital biliary atresia, 3 cases of small gallbladder, 1 case of gallstone and one case of irregular size of gallbladder. There are 9 cases who underwent prenatal diagnosis, with 4 cases of abnormal result. Conclusion Prenatal ultrasound plays a role in the early recognize of abnormal gallbladder, which will improve the postnatal prognosis.

\section{Introduction}

The gallbladder origins from the hepatic diverticulum on the ventral side of the primitive midgut at the fourth week of embryonic development and begins cavitation into a cystic structure at the twelfth week [1]. Therefore, theoretically, the morphological structure of the gallbladder can be viewed by prenatal ultrasound from the first trimester of pregnancy. In 1987, Hata et al. published a paper describing the ultrasonic characteristics of the foetal gallbladder for the first time and found that the gallbladder detection rates at weeks $20-23$ and weeks $24-27$ of pregnancy were $37.5 \%$ and $64.7 \%$ respectively ${ }^{[2]}$. In recent years, some studies have reported gallbladder detection rates of $99.9 \%$ at $14-16$ weeks ${ }^{[3,4]}$ by transvaginal ultrasonography, while $95 \%$ at $24-32$ weeks of pregnancy by transabdominal ultrasonography ${ }^{[5]}$.

Non-visualization of the foetal gallbladder (NVFGB), which has a prevalence of $0.1-0.15 \%$, refers to the inability to observe the foetal gallbladder in 2 or more consecutive ultrasound examinations within 1 week during pregnancy and ${ }^{[3,4]}$. In most cases, the foetal gallbladder will be located during the subsequent ultrasound or postnatal ultrasound examinations, but there are also reports suggesting that NVFGB is associated with gallbladder dysplasia, biliary atresia, cystic fibrosis, chromosome anomalies and intestinal obstruction ${ }^{[6]}$.

The purpose of this study was to summarize and discuss the clinical diagnosis, treatment and prognosis of NVFGB in Chinese population.

\section{Data and methods}

\subsection{Study subjects}

In this study, clinical data of 65 foetuses who were initially diagnosed with NVFGB by ultrasound at the Department of Obstetrics and Gynaecology, Peking University First Hospital, from January 2019 to 
December 2020 were collected retrospectively. Among them, 16 patients failed to follow-up, including 1 case of late inevitable abortion and 15 cases of refusal to follow-up.

\subsection{Instruments and study methods}

1.2.1 Instruments and Ethic statement In this study, E6, E8 and E10 ultrasonic diagnostic instruments manufactured by GE USA were used; the probe frequency ranged from 1.5 to $6.0 \mathrm{MHz}$. All scans were performed by certified radiologists with at least 5 years of experience in foetal ultrasound. The study was conducted according to the guidelines of the Declaration of Helsinki, and approved by the Institutional Review Board of Peking University First Hospital (protocol code 2013[572]). Informed consent was obtained from all patients.

1.2.2 Methods to examine foetal gallbladder When being scanned by ultrasound, the gallbladder is at the abdominal circumference plane and slightly inclined toward the back of the foetus simultaneously. It is normally on the right side umbilical vein ${ }^{[7]}$. In gray-scale imaging, the gallbladder is a hypoechoic area with the presence of cystical wall. The shape varies, including teardrop, rectangle, spindle, annulus, etc. ${ }^{[8]}$. Colour Doppler ultrasound was used to distinguish the gallbladder from the intra-abdominal segment of the umbilical vein. NVFGB was diagnosed if no gallbladder was observed in 2 or more ultrasound examinations within 1 week.

1.2.3 Ultrasonic examinations of other foetal structures If NVFGB was diagnosed during the ultrasonic examination, the other foetal anomalies were further examined in details according to the ultrasonic examination guidelines by the International Society of Ultrasound in Obstetrics and Gynaecology. For pregnant women complicated with foetal structural anomalies, our centre provided prenatal consultation and prenatal diagnosis. The decision whether to conduct an invasive prenatal diagnosis was made by the patient and her families.

1.2.4 Clinical data collection this study is approved by the the Institutional Review Board of the First Hospital, Peking University. The project number is 2013 [572], and the date of approval is May 2nd, 2013.For all patients, the relevant clinical data were collected including age, gravidity and parity history, method of fertilization, gestational age at initial finding of NVFGB, other foetal structural anomalies, pregnancy outcomes, gestational age at birth, birth weight and follow-up after birth, etc. Telephone follow-up was conducted after birth, and the follow-up content included general condition after birth and further treatments after birth. The last follow-up occurred on January 25, 2021.

1.2.5 A descriptive analysis was conducted using the clinical data of NVFGB cases. The median (minimum-maximum) is presented for count data, and the mean ( \pm standard deviation) is presented for measurement data.

\section{Results}

\subsection{General data}

The average age of the 49 pregnant women included in this study was 30 years, and the mean gestational age at which NVFGB was observed for the first time was 26 weeks (Table 1). 
Among the 28 cases of persistent NVFGB, 11 cases were complicated with other foetal structure anomalies. Among them, 7 were complicated with foetal heart structure anomalies, including tetralogy of Fallot, the absence of ductus arteriosus, persistent left superior vena cava, right aortic arch, and common arterial trunk, ventricular septal defects, aortic stenosis, etc. These 7 pregnancies were all terminated. Likewise, the case of urinary anomaly (horseshoe kidney was complicated with aortic stenosis, which was terminated. Three foetueses of foetal abdomen anomalies, including intestinal canal widening, ovarian cyst in the right lower abdomen and anal atresia, were all live births and their gallbladders were located after birth. The foetus with anal atresia underwent surgical repair after birth. In the foetus with the ovarian cyst, the size of the cyst reduced 6 months after birth. One case with a nervous system anomaly (open spina bifida) was terminated.

Among the 17 cases of isolated NVFGB, one case was diagnosed of type 3 congenital biliary atresia after birth, while another 5 cases involved gallbladder anomalies such as a small gallbladder $(n=3)$, gallstones $(n=1)$ and an irregular gallbladder shape with multiple mediastina in the gallbladder $(n=1)$, were still under follow-up. The gallbladder of the remaining 10 cases (59\%) were noted after birth.

In another 21 cases, the gallbladder was located during subsequent follow-ups during the pregnancy period, among which 3 cases complicated with other foetal structural malformations, including 1 case of ventricular septal defect, 1 case of foetal hydronephrosis and 1 case of intestinal canal widening; the case of intestinal canal widening was ultimately diagnosed as jejunal septum atresia and poor intestinal torsion after birth.

2.3 Analysis of the prenatal diagnosis of NVFGB

In this study, 9 patients agreed to undergo amniocentesis; the results for 4 of these patients were abnormal (Table 2).

\section{Discussion}

The incidence of NVFGB during pregnancy is low. Relevant articles published in China and abroad is scarce, most of which were case series report ${ }^{[3,6,8-12]}$. Studies indicate that most NVFGB during pregnancy is temporary. In the study by Di Pasquo, et al., $75 \%$ of foetal gallbladders were located during later follow-ups ${ }^{[13]}$. In our study, 69\% (34/49) of foetal gallbladders were located after subsequent followups. The percentage was slightly lower than that in the literature is possibly due to the early termination of pregnancy in some cases. The temporary invisible gallbladder in prenatal ultrasound might be associated with the temporary contraction of the gallbladder ${ }^{[14]}$.

In a multicentre retrospective study published by Dreux et al. in 2012, a total of 8 patients (7.8\%) were diagnosed as congenital biliary atresia, of whom $5(5.9 \%, 5 / 85)$ were not complicated with other structural anomalies based on prenatal ultrasound examinations ${ }^{[6]}$. Among the foetuses with isolated 
NVFGB in this study, only 1 (4\%) was diagnosed with biliary atresia after birth. The patient underwent the Kasai procedure 40 days after birth, but the outcome after the operation was poor. Liver transplantation was then carried out 3 months after birth. The infant now is in good condition. Congenital biliary atresia is a serious neonatal disease with an incidence $0.5-0.8 / 10,000$ live births in Western countries ${ }^{[15,16]}$ and a relatively high incidence of 1.1-1.5/10,000 live births in Asian countries ${ }^{[17,18]}$. Based on the atresia location, biliary atresia can be divided into type I (5\%, atresia located at the level of the common bile duct), type II ( $2 \%$, atresia located at the level of the common hepatic duct) and type III $(>90 \%$, atresia located at the level of the hepatic portal vein, with typical ultrasonic manifestation of no gallbladder or a small gallbladder). If not identified and treated in a timely manner, the disease will lead to serious complications and even death [19]. The Kasai procedure can significantly improve the prognosis of newborns; the best operation date is within $60 \mathrm{~d}$ after birth, resulting in a 10-year survival rate as high as $70 \%$ [20]. Liver transplantation can be performed if the surgical outcome is poor. As reported in the literature, the 1-year survival rate and the 3-year survival rate after liver transplantation are $90 \%$ and $88 \%$, respectively ${ }^{[21]}$.

The existing literature indicates that NVFGB is an ultrasound finding of cystic fibrosis during pregnancy $[6,22,23]$. However, this disease was not observed in all foetuses in this study, which may be related to the ethnicity of the study population. Cystic fibrosis has high incidence rates in Europe, North America and Australia, and it is the most common fatal genetic disease leading to lung diseases, digestive system obstruction, pancreatic dysplasia, infertility, etc. ${ }^{[24]}$ It is caused by a mutation in the cystic fibrosis transmembrane conductance regulator (CFTR) gene ${ }^{[25]}$. The protein encoded by CFTR is involved in regulating sodium/chlorine channels in epithelial cells ${ }^{[26]}$. The main prenatal ultrasound manifestations are foetal digestive system anomalies, such as intestinal canal echo enhancement, intestinal canal widening and NVFGB. In a study conducted by Becdelièvre A, NVFGB + intestinal canal echo enhancement + intestinal canal widening has a high predictive value for the prenatal diagnosis of cystic fibrosis (likelihood ratio, 31.4) ${ }^{[22]}$. Bergougnoux et al. summarized the prenatal ultrasound features of 37 children with cystic fibrosis and found that $5(13.5 \%)$ cases only had isolated NVFGB ${ }^{\text {[27]; }}$ CFTR gene testing through invasive prenatal diagnosis is required for the final diagnosis of cystic fibrosis. Although the incidence of this disease is low in China, with the increase in global population mobility and the unpredictability of gene mutations, invasive prenatal diagnosis should be considered when NVFGB is observed during pregnancy, especially when it is complicated with other digestive system anomalies.

Researchers have studied the correlation between the concentrations of digestive enzymes in amniotic fluid, such as gamma-glutamyl transpeptidase, aminopeptidase-M, and intestinal alkaline phosphatase, with biliary atresia, cystic fibrosis and digestive system obstruction ${ }^{[3,8-10,28]}$. A systematic review by Di Pasquo concluded that the positive and negative predictive values of decreased concentrations of gamma-glutamyl transpeptidase and intestinal alkaline phosphatase in amniotic fluid for predicting biliary atresia or cystic fibrosis before 22 gestational weeks were $69 \%-100 \%$ and $94 \%-100 \%$ respectively. However, the results for amniotic fluid after 22 gestational weeks demonstrated reduction in both positive 
$(62 \%)$ and negative (88\%) predictive values ${ }^{[13]}$. Therefore, there are still limitations in diagnosis by amniotic fluid biomarkers. Furthermore, the amount of amniotic fluid itself will affect the concentrations of biomarkers.

In our study, only 9 foetuses underwent invasive prenatal testing during pregnancy, and 4 of 9 were found to have abnormal results, including one with isolated NVFGB (patients 1 and 2), one complicated with a ventricular septal defect (patient 3, copy number variation with unknown clinical significance) and one complicated with open spina bifida (patient 4, trisomy mosaicism). Some case reports have described a correlation between the absence of a gallbladder and chromosomal anomalies. The most common chromosomal anomalies include trisomy $8 p^{[29]}$, partial trisomy $16 q^{[30]}$, trisomy $16^{[31]}$, trisomy $22^{[32]}$, trisomy $47^{[33]}$, etc. However, in those studies, foetuses were complicated with other ultrasonic structural anomalies. In studies of the prenatal diagnosis of isolated NVFGB, Bronstein et al. ${ }^{[4]}$ and Blazer et al. ${ }^{[3]}$ did not find chromosome anomalies in the prenatal diagnosis of isolated NVFGB. Ochshorn et al. summarized the prenatal diagnosis results of 17 cases of isolated NVFGB and found only one case of 47, $X X X{ }^{[9]}$. Lena, et al. performed chromosomal microarray analysis (CMA) of 45 foetuses with isolated NVFGB and found only 1 abnormal result indicating pathological CMA, but its relationship with gallbladder development was uncertain; the other 2 abnormal CMA results had no clear clinical significance. The incidence of abnormal CMA results was not significantly different from that in the normal population ${ }^{[11]}$. At present, there are few studies regarding the abnormal development of the foetal gallbladder and abnormal chromosome genes. The clinical significance of genetic anomalies in published articles is still unclear. It is necessary to accumulate further data to help guide prenatal consultations.

However, the limitation of this study is that, firstly. It is a retrospective study based on data from a single tertiary centre, resulting in small numbers of abnormal cases and bias. Secondly, the genetic results were obtained from only 9 foetuses. Last but not the least, the follow-up should be continued in the future.

Based on the results of this study and literature review, the authors propose that prenatal ultrasound plays an important role in detecting gallbladder anomalies and improving patient prognosis. More than half of NVFGB could be located in the follow-ups, either prenatally and postnatally. Other structures, especially the heart (foetal echocardiography), intestinal canal and urinary system, should be carefully examined when NVFGB is suspected. Meantime, patients and their families should be provided with the choice of an invasive prenatal diagnosis. Additionally, patients with isolated NVFGB during pregnancy should be informed that there is still a possibility (3-6\%) of a congenital biliary atresia diagnosis after birth and that the prognosis of patients after the operation is good ${ }^{[13]}$.

\section{Declarations}

\section{Author contributions}


HJZ designed the research and drafted the manuscript. XYZ and JLK performed a detailed data collection and literature search. YS provided substantial edits and additions to the manuscript. HXY and YS were chief director of maternal and fetal unit, and participated in its design and coordination. All authors have accepted responsibility for the entire content of this manuscript and approved its submission.

\section{Competing interests}

The authors declare that they have no competing interests.

\section{Funding Statement}

this research received no specific grant from any funding agency in the public, commercial or not-forprofit sectors.

\section{References}

1. Ando H. Embryology of the Biliary Tract[J]. Digestive Surgery, 2010, 27(2): 87-89.

2. Hata K, Aoki S, Hata T, et al. Ultrasonographic Identification of the Human Foetal Gallbladder in utero[J]. Gynaecologic and obstetric investigation, 1987, 23(2): 79-83.

3. Blazer S, Zimmer EZ, Bronshtein M. Nonvisualization of the foetal gallbladder in early pregnancy: Comparison with clinical outcome[J]. Radiology, 2002, 224(2): 379-382.

4. Bronshtein $\mathrm{M}$, Weiner $\mathrm{Z}$, Abramovici $\mathrm{H}$, et al. Prenatal diagnosis of gall bladder anomalies-report of 17 cases[J]. Prenatal diagnosis, 1993, 13(9): 851-861.

5. Hertzberg BS, Kliewer MA, Maynor C, et al. Nonvisualization of the foetal gallbladder: frequency and prognostic importance[J]. Radiology, 1996, 199(3): 679-682.

6. Dreux S, Boughanim M, Lepinard C, et al. Relationship of non-visualization of the foetal gallbladder and amniotic fluid digestive enzymes analysis to outcome[J]. Prenat Diagn, 2012, 32(5): 423-426.

7. Wang Y. Prenatal ultrasonic diagnosis of gallbladder anomalies [J]. Chinese Journal of Medical Ultrasound (Electronic Edition), 2011, (11).

8. Bardin R. Nonvisualization of the Foetal Gallbladder: Can Levels of Gamma-Glutamyl Transpeptidase in Amniotic Fluid Predict Foetal Prognosis?[J]. Foetal diagnosis and therapy, 2016, 39(1): 50-55.

9. Ochshorn Y, Rosner G, Barel D, et al. Clinical evaluation of isolated nonvisualized foetal gallbladder[J]. Prenat Diagn, 2007, 27(8): 699-703.

10. Shen $\mathrm{O}$, Rabinowitz R, Yagel S, et al. Absent gallbladder on foetal ultrasound: prenatal findings and postnatal outcome[J]. Ultrasound Obstet Gynecol, 2011, 37(6): 673-677.

11. Sagi-Dain L, Singer A, Hadid Y, et al. Non-visualization of foetal gallbladder in microarray era - a retrospective cohort study and review of the literature[J]. J Matern Foetal Neonatal Med, 2019, 32(16): 2643-2648. 
12. Geng J, Cao J, Zhang J, et al. Prenatal diagnosis and clinical prognosis of non-visualization of the foetal gallbladder [J]. Chinese Journal of Prenatal Diagnosis (Electronic Version), 2019, 11(3): 1822.

13. Di Pasquo E, Kuleva M, Rousseau A, et al. Outcome of non-visualization of foetal gallbladder on second-trimester ultrasound: cohort study and systematic review of literature[J]. Ultrasound Obstet Gynecol, 2019, 54(5): 582-588.

14. Wang $Y, L i ~ S$, Chen $C$, et al. Diagnosis and clinical evaluation of gallbladder anomalies by prenatal ultrasound screening [J]. Chinese Journal of Medical Ultrasound (Electronic Edition), 2012, 09 (5): 433-438.

15. Hartley JL, Davenport M, Kelly DA. Biliary atresia[J]. Lancet, 2009, 374(9702): 1704-1713.

16. Nizery L, Chardot C, Sissaoui S, et al. Biliary atresia: Clinical advances and perspectives[J]. Clin Res Hepatol Gastroenterol, 2016, 40(3): 281-287.

17. Chiu CY, Chen PH, Chan CF, et al. Biliary atresia in preterm infants in Taiwan: a nationwide survey[J]. J Pediatr, 2013, 163(1): 100-103.e101.

18. Wada H, Muraji T, Yokoi A, et al. Insignificant seasonal and geographical variation in incidence of biliary atresia in Japan: a regional survey of over 20 years[J]. J Pediatr Surg, 2007, 42(12): 20902092.

19. Sanchez-Valle A, Kassira N, Varela VC, et al. Biliary Atresia: Epidemiology, Genetics, Clinical Update, and Public Health Perspective[J]. Advances in Paediatrics, 2017, 64(1): 285-305.

20. Ohi R, Nio M, Chiba T, et al. Long-term follow-up after surgery for patients with biliary atresia[J]. J Pediatr Surg, 1990, 25(4): 442-445.

21. Utterson EC, Shepherd RW, Sokol RJ, et al. Biliary atresia: clinical profiles, risk factors, and outcomes of 755 patients listed for liver transplantation[J]. J Pediatr, 2005, 147(2): 180-185.

22. de Becdelièvre A, Costa $C$, Jouannic JM, et al. Comprehensive description of CFTR genotypes and ultrasound patterns in 694 cases of foetal bowel anomalies: a revised strategy[J]. Hum Genet, 2011, 129(4): 387-396.

23. Duguépéroux I, Scotet $V$, Audrézet MP, et al. Nonvisualization of foetal gallbladder increases the risk of cystic fibrosis[J]. Prenat Diagn, 2012, 32(1): 21-28.

24. Elborn JS. Cystic fibrosis[J]. Lancet, 2016, 388(10059): 2519-2531.

25. Riordan JR, Rommens JM, Kerem B, et al. Identification of the cystic fibrosis gene: cloning and characterization of complementary DNA[J]. Science, 1989, 245(4922): 1066-1073.

26. Welsh MJ, Smith AE. Molecular mechanisms of CFTR chloride channel dysfunction in cystic fibrosis[J]. Cell, 1993, 73(7): 1251-1254.

27. Bergougnoux A, Jouannic JM, Verneau F, et al. Isolated Nonvisualization of the Foetal Gallbladder Should Be Considered for the Prenatal Diagnosis of Cystic Fibrosis[J]. Foetal Diagn Ther, 2019, 45(5): 312-316. 
28. Dreux S, Salomon LJ, Muller F, et al. Second-trimester maternal serum markers and placenta accreta[J]. Prenat Diagn, 2012, 32(10): 1010-1012.

29. Fryns JP, Petit P, Moerman F, et al. 8p trisomy in a malformed foetus[J]. Ann Genet, 1982, 25(3): 162163.

30. Hatanaka K, Ozaki M, Suzuki M, et al. Trisomy $16 q 13--q$ ter in an infant from a t(11;16)(q25;q13) translocation-carrier father[J]. Hum Genet, 1984, 65(3): 311-315.

31. Moradkhani K, Puechberty J, Blanchet P, et al. Mosaic trisomy 16 in a foetus: the complex relationship between phenotype and genetic mechanisms[J]. Prenat Diagn, 2006, 26(12): 11791182.

32. Gangbo E, Lacombe D, Alberti EM, et al. Trisomy 22 with thyroid isthmus agenesis and absent gall bladder[J]. Genet Couns, 2004, 15(3): 311-315.

33. Matheson JK, Matheson VA, McCorquodale M, et al. Prenatal diagnosis of double autosomal mosaicism $(47, \mathrm{XX},+8 / 47, \mathrm{XX},+14)$ : phenotype and molecular cytogenetic analysis on different tissues[J]. Foetal Diagn Ther, 2003, 18(1): 29-32.

\section{Tables}

Table 1 Demographic data and pregnancy characteristics of the study population

\begin{tabular}{|c|c|}
\hline Clinical data & Value \\
\hline Age & $30.78( \pm 4.19)$ \\
\hline \multicolumn{2}{|l|}{ Fertilization mode } \\
\hline Natural pregnancy & $45(91.8 \%)$ \\
\hline Assisted reproductive technology & $4(8.2 \%)$ \\
\hline Singleton & $45(91.8 \%)$ \\
\hline Twins & $4(8.2 \%)$ \\
\hline Gestational age at initial finding of NVFGB & $26.22( \pm 4.72)$ \\
\hline Complicated with other foetal structural anomalies & $14(28.6 \%)$ \\
\hline \multicolumn{2}{|l|}{ Pregnancy outcomes } \\
\hline Live birth & $39(79.6 \%)$ \\
\hline Pregnancy termination & $10(20.4 \%)$ \\
\hline
\end{tabular}

Table 2 Analysis of prenatal diagnosis results of NVFGB 


\begin{tabular}{|c|c|c|c|}
\hline Case & Genetic results & $\begin{array}{l}\text { Ultrasonic feature during } \\
\text { pregnancy }\end{array}$ & Pregnancy outcome \\
\hline 1 & $\begin{array}{l}\text { Arr [hg19] 5p14.3 } \\
(21529026-22296824) \\
x 1\end{array}$ & $\begin{array}{l}\text { Persistent NVFGB during } \\
\text { pregnancy }\end{array}$ & $\begin{array}{l}\text { Live birth, type } 3 \text { congenital } \\
\text { biliary atresia }\end{array}$ \\
\hline 2 & $\begin{array}{l}\text { Arr [GRCh37] } \\
2 q 22.1 q 22.2 \\
\left(141798723 \_42726446\right) \\
x 1\end{array}$ & $\begin{array}{l}\text { Twin reversed arterial } \\
\text { perfusion sequence (TRAPS), } \\
\text { persistent NVFGB during } \\
\text { pregnancy }\end{array}$ & $\begin{array}{l}\text { Live birth, generally good } \\
\text { condition, results consistent } \\
\text { with aCGH results for the } \\
\text { father }\end{array}$ \\
\hline 3 & $\begin{array}{l}\text { Arr [hg19] 18q21.1 } \\
(44396913-44701650) \\
\times 1 \text {, deletion } 0.304 \mathrm{Mb}\end{array}$ & $\begin{array}{l}\text { Visible gallbladder late in } \\
\text { pregnancy, complicated with a } \\
\text { ventricular septal defect }\end{array}$ & $\begin{array}{l}\text { Live birth, ventricular septal } \\
\text { defect repair }\end{array}$ \\
\hline 4 & $47, X X+9[44] / 46, X X[34]$ & $\begin{array}{l}\text { Persistent NVFGB complicated } \\
\text { with open spina bifida }\end{array}$ & Termination of pregnancy \\
\hline
\end{tabular}

\section{Figures}

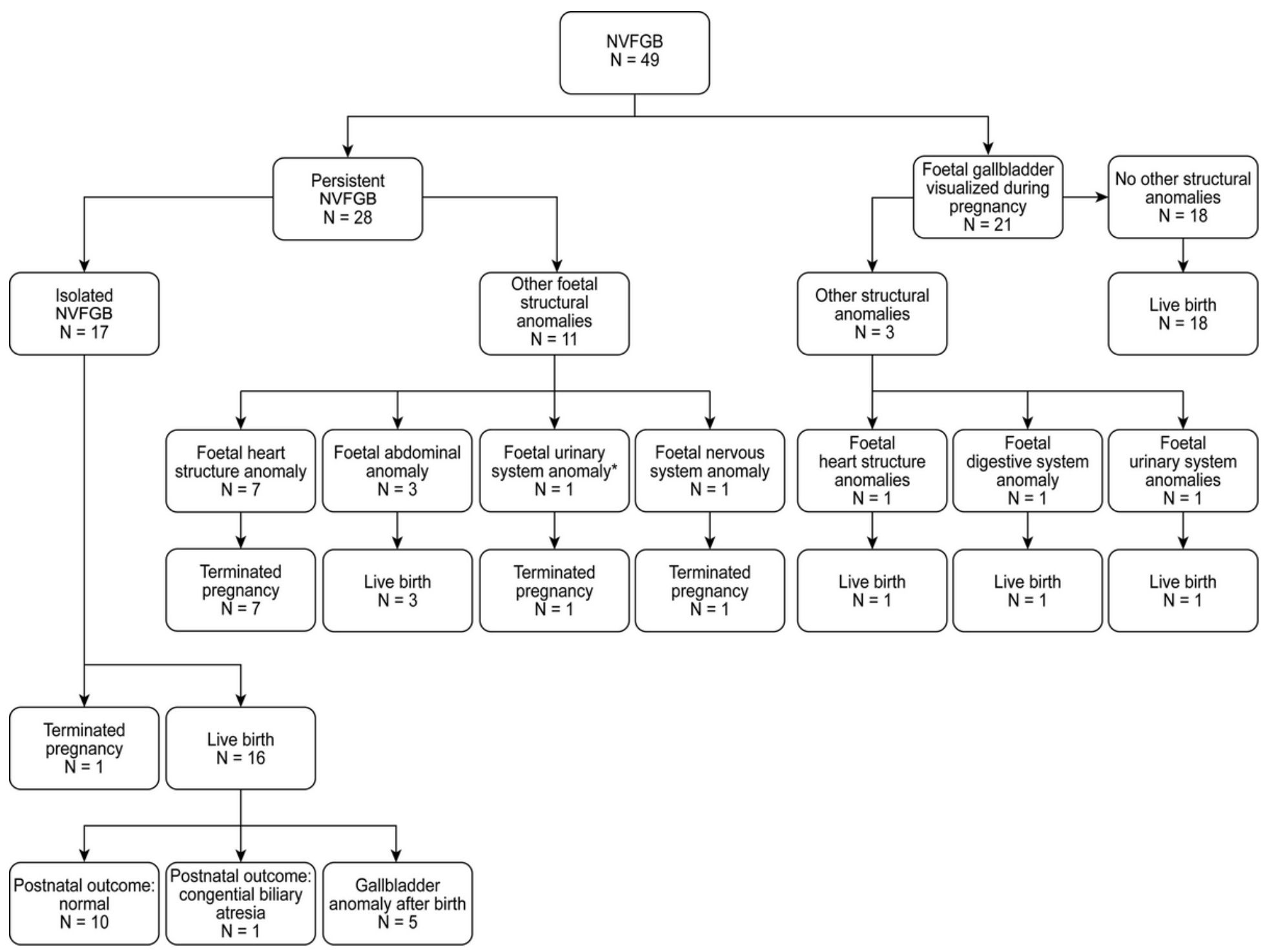




\section{Figure 1}

pregnancy outcomes of 49 foetus with NVFGB. NVFGB, non-visualization of foetal gallbladder 